\title{
Sintomatologia musculoesquelética dos enfermeiros no contexto hospitalar: contributo do enfermeiro de reabilitaçáo
}

Musculoskeletal symptoms of hospital nurses: contribution of rehabilitation nurses Síntomas musculoesqueléticos de los enfermeros en el contexto hospitalario: contribución del enfermero de rehabilitación

Maria Isabel Rebelo Lopes de Moura*(D); Maria Manuela Ferreira Pereira da Silva Martins**iD;

Olga Maria Pimenta Lopes Ribeiro*** (iD

\section{Resumo}

Enquadramento: Os enfermeiros integram a classe profissional maioritária no Serviço Nacional de Saúde, sendo que o trabalho que desenvolvem condiciona o seu bem-estar musculoesquelético.

Objetivo: Conhecer a prevalência da sintomatologia musculoesquelética dos enfermeiros, identificando simultaneamente os fatores de risco.

Metodologia: Estudo quantitativo, de carácter descritivo e correlacional, concretizado num centro hospitalar de Portugal. A técnica de amostragem foi não probabilística por conveniência, obtendo-se uma amostra de 260 enfermeiros. Como instrumento de colheita de dados utilizou-se o questionário, dividido em duas partes (dados sociodemográficos/profissionais e Questionário Nórdico Musculoesquelético).

Resultados: A maioria dos enfermeiros $(65,1 \%)$ apresenta sintomatologia ao nível do sistema musculoesquelético, sendo que a coluna lombar é o segmento mais afetado. O género feminino, o aumento da idade, do índice de massa corporal, do tempo de exercício profissional e a carga horária estão relacionados com o agravamento dos sintomas. Conclusáo: Os resultados apontam para a necessidade de sensibilizar os enfermeiros para os fatores de risco, bem como incentivar a adoção de estratégias, como a ginástica laboral, para minimizar sintomatologia musculoesquelética.

Palavras-chave: enfermeiras e enfermeiros; hospitais; fatores de risco; dor musculoesquelética

\section{Abstract}

Background: Nurses make up the major professional category in the National Health Service, and their work affects their musculoskeletal well-being.

Objective: To determine the prevalence of musculoskeletal symptoms of nurses and identify their risk factors. Methodology: A quantitative, descriptive, and correlational study, conducted in a Portuguese hospital center, used a non-probabilistic sample by convenience of 260 nurses. A questionnaire was used as data collection instrument, divided into two parts (sociodemographic and professional data/Nordic Musculoskeletal Questionnaire). Results: The majority of nurses (65.1\%) manifests musculoskeletal symptoms, the lumbar spine being the most affected body segment. The female gender, aging, body mass index, time of professional experience, and workload are related to the worsening of symptoms.

Conclusion: The results point out the need to raise awareness of the risk factors among nurses, as well as to promote the adoption of strategies, like workplace gymnastics, to minimize musculoskeletal symptoms.

Keywords: nurses; hospitals; risk factors; musculoskeletal pain

*MSc., Enfermeiro, Centro Hospitalar de Trás-os-Montes e Alto Douro, 5000-508, Vila Real, Portugal [isabelmoura1992@gmail.com]. (D https://orcid.org/0000-0002-9614-8848. Contribuição no artigo: pesquisa bibliográfica; planeamento da metodologia; recolha de dados; tratamento e avaliação estatística; análise dos dados; discussão dos resultados e escrita do artigo. Morada para correspondência: Lugar do Rendeiro - Cumieira, 5030-075, Santa Marta de Penaguião, Vila Real, Portugal.

**Ph.D., Professora Coordenadora, Escola Superior de Enfermagem do Porto, 4200-072 Porto, Portugal [mmartins@esenf.pt]. (D) https://orcid.org/0000-0001-5530-3891. Contribuição no artigo: planeamento da metodologia; tratamento e avaliação estatística; análise dos dados; discussão dos resultados e revisão do artigo.

***Ph.D., Professora Adjunta, Escola Superior de Enfermagem do Porto, 4200-072, Porto, Portugal [olgaribeiro25@hotmail.com].D https://orcid.org/0000-0001-9982-9537.Contribuicão no artigo: planeamento da metodologia; tratamento e avaliação estatística; análise dos dados; discussão dos resultados e revisão do artigo.

\section{Resumen}

Marco contextual: Los enfermeros forman parte de la clase profesional mayoritaria del Servicio Nacional de Salud, y su trabajo condiciona su bienestar musculoesquelético.

Objetivo: Conocer la prevalencia de la sintomatología musculoesquelética de los enfermeros, mediante la identificación simultánea de los factores de riesgo.

Metodología: Estudio cuantitativo, descriptivo y correlacional realizado en un centro hospitalario de Portugal. La técnica de muestreo fue no probabilística por conveniencia, y se obtuvo una muestra de 260 enfermeros. Como instrumento de recopilación de datos se utilizó el cuestionario, dividido en dos partes (datos sociodemográficos/profesionales y el Cuestionario Nórdico Musculoesquelético).

Resultados: La mayoría de los enfermeros $(65,1 \%)$ presenta síntomas a nivel del sistema musculoesquelético, y la columna lumbar es el segmento más afectado. El sexo femenino, el aumento de la edad, el índice de masa corporal, el tiempo de ejercicio profesional y la carga de trabajo están relacionados con el empeoramiento de los síntomas.

Conclusión: Los resultados apuntan a la necesidad de concienciar a los enfermeros sobre los factores de riesgo, así como de fomentar la adopción de estrategias, como la gimnasia en el lugar de trabajo, para minimizar la sintomatología musculoesquelética.

Palabras clave: enfermeras y enfermeros; hospitales; factores de riesgo; dolor musculoesquelético

Recebido para publicação em: 18.06 .19

Aceite para publicação em: 03.09.19 


\section{Introdução}

Os enfermeiros são a classe profissional, da área da saúde, que mais padecem com as lesóes musculoesqueléticas, devido à exigência física que o seu trabalho acarreta, às posturas incorretas e por trabalharem com equipamentos antiquados (Fernandes, Couto, Carvalho, Fernandes, \& Ferreira, 2018). Estas lesōes caracterizam-se como um conjunto de doenças inflamatórias e degenerativas do sistema locomotor, resultantes da ação de fatores de risco profissionais, tais como a repetibilidade, a sobrecarga e/ou a postura adotada durante o exercício profissional, manifestando-se através de sintomatologia de dor, edema, diminuição da força muscular e do movimento articular (Martins, 2008; Direcção-Geral da Saúde, 2008). Segundo a American Nurses Association (ANA, 2011), os profissionais de enfermagem apresentam uma taxa elevada de sintomatologia musculoesquelética, mesmo após serem melhoradas as condiçóes do local de trabalho onde exercem a profissão. A mesma associação, lembra que os enfermeiros necessitam de maior consciencialização para o uso de equipamentos de auxílio à prática de cuidados, pois menos de um terço os utiliza com frequência (ANA, 2011). Assim, na sequência da observação das práticas profissionais, bem como da sintomatologia musculoesquelética dos enfermeiros, considerou-se relevante o estudo das condicionantes do bem-estar musculoesquelético dos enfermeiros no exercício da sua atividade no contexto hospitalar. Este estudo teve em consideração o facto de muitos enfermeiros apresentarem uma taxa de absentismo de 10,19\% (Oliveira, 2017), sendo que as principais causas se devem a motivos de doença. Neste sentido, pretendemos conhecer a prevalência da sintomatologia musculoesquelética dos enfermeiros, identificando simultaneamente os fatores de risco.

\section{Enquadramento}

Os enfermeiros são os profissionais de saúde que mais tempo passam no cuidado aos doentes, estando por isso mais expostos a um grande número de riscos que podem contribuir para o desenvolvimento de lesóes musculoesqueléticas ligadas ao trabalho. De facto, durante a prestação de cuidados, o enfermeiro assiste as pessoas doentes na concretização das atividades inerentes aos diversos autocuidados, tais como o banho, o levante, a transferência e o posicionamento, que podem resultar em lesôes para o sistema musculoesquelético, sendo importante que o enfermeiro esteja desperto para os diferentes riscos associados à prática do cuidar (Carpenter \& Dawson, 2015; Neves \& Serranheira, 2014). As lesóes musculoesqueléticas são síndromes de dor crónica que podem afetar diferentes segmentos corporais, sendo que a sintomatologia surge gradualmente e agrava no final do dia de trabalho ou durante os picos de execução, aliviando com as pausas e com o repouso (Direcção-Geral da Saúde, 2008). Segundo Agência Europeia para a Segurança e Saúde de Trabalho (AESST, 2019), estas lesões desenvolvem-se ao longo do tempo, resultantes da combinação de vários fatores como movimentos repetidos, aplicação de força, posturas inadequadas e do stress relacionado com o trabalho. Jerónimo e Cruz (2014) referem que existem fatores de risco para o desenvolvimento de lesôes musculoesqueléticas, nomeadamente a nível individual (género, idade, características antropométricas); risco biomecânico (a postura e os movimentos repetitivos); riscos psicossociais (provenientes do stress, como a sobrecarga do trabalho, à pressão do tempo e ao trabalho por turnos) e riscos organizacionais (número de horas extraordinárias, períodos prolongados de trabalho, intervalos de descanso ausentes ou insuficientes). Neste contexto, os enfermeiros apresentam alta probabilidade de desenvolver sintomatologia musculoesquelética nos diversos segmentos anatómicos (Cordeiro, 2015; Torres, Carneiro, \& Arezes, 2017). Cordeiro (2015), citando outros autores, refere que existem quatro estádios no processo de evolução dos sintomas musculoesqueléticos, sendo que no estádio I, a pessoa apresenta um desconforto e dor espontânea na zona afetada, melhorando com o repouso; no estádio II, a dor é mais intensa e persistente durante as horas de trabalho, podendo estar acompanhada por sinais de parestesias e calor; no estádio III a intensidade da dor aumenta de forma persistente, com a presença de edema e alteração da sensibilidade e no estádio IV a dor é contínua e intolerável, com a presença de edema e possibilidade de atrofia e deformidade, sendo que a capacidade 
de trabalho no indivíduo estará condicionada. Assim, a AESST (2019) recomenda medidas preventivas para evitar as lesóes musculoesqueléticas, sendo elas a disposição do local de trabalho, nomeadamente na adaptação para melhorar as posturas adotadas; equipamentos ergonómicos e adequados para a realização das atividades; reforçar a sensibilização para os riscos que o local de trabalho apresenta, com o objetivo de desenvolver uma política de prevenção e combate às lesões musculoesqueléticas. A ginástica laboral é também uma das medidas que tem sido mencionada por diversos autores, como Ribeiro (2015) e Duarte, Gonçalves, Ferreira, e Cunha (2017), por apresentar inúmeros benefícios para o trabalhador e para a entidade empregadora, visto que é considerada eficaz na prevenção de lesôes musculoesqueléticas, na redução de acidentes de trabalho, na redução do absentismo e no aumento da produtividade, melhorando a qualidade de vida do enfermeiro, através da sua satisfação e motivação (Santos \& Almeida, 2012). Pelo papel que desempenha na equipa, cabe ao Enfermeiro Especialista de Enfermagem de Reabilitaçâo (EEER) identificar e contribuir para a resolução dos problemas que possam pôr em causa o bem-estar musculoesquelético dos enfermeiros, pois este interage com a pessoa de forma a desenvolver atividades que permitam maximizar as suas capacidades funcionais, melhorar o desempenho motor e cardiorrespiratório e potencializar o rendimento e o desenvolvimento pessoal (Regulamento n. ${ }^{\circ}$ 350/2015).

\section{Questóes de investigação}

Qual a prevalência da sintomatologia musculoesquelética dos enfermeiros no contexto hospitalar? Que fatores de risco individuais e organizacionais estão relacionados com a sintomatologia musculoesquelética?

\section{Metodologia}

Trata-se de um estudo quantitativo de caráter descritivo e correlacional realizado num Centro Hospitalar $(\mathrm{CH})$ da regiāo norte de Portugal. A população refere-se aos enfermeiros que exercem nos serviços de internamento desse
$\mathrm{CH}$ (medicina, especialidades médicas, cirurgia, especialidades cirúrgicas, unidade de cuidados intensivos coronários e unidade internamento de doenças infeciosas), que, até à data do pedido de autorização, eram 427 enfermeiros. Importa referir que foram excluídos os profissionais que se encontravam em licença, independentemente do motivo, bem como os enfermeiros que apresentavam experiência profissional inferior a 1 ano. A técnica de amostragem utilizada no estudo foi não probabilística por conveniência, tendo-se obtido uma amostra de 260 enfermeiros (correspondente a $60,9 \%$ ), pelo que se verifica uma confiabilidade de $95 \%$ para uma margem de erro de 3,81\%. O estudo foi autorizado pela comissão de ética, de acordo com o parecer n. ${ }^{\circ}$ 170/2018. Como instrumento de colheita de dados foi utilizado um questionário. A primeira parte do questionário diz respeito aos dados sociodemográficos e profissionais dos enfermeiros que compóem a amostra e na segunda parte foi utilizada o Questionário Nórdico Musculoesquelético (QNM), adaptado e validado por Mesquita, Ribeiro, e Moreira (2010). A colheita de dados foi concretizada no mês de maio de 2018. Importa referir que os enfermeiros que exerciam funções nos serviços onde se realizou o estudo foram esclarecidos sobre os objetivos e sobre os procedimentos inerentes à investigação. Para o tratamento e análise dos dados foi realizada uma matriz de dados através do programa de estatística IBM SPSS Statistics, versão 25.0, permitindo posteriormente a operacionalização e correlação das variáveis. Estatisticamente, utilizaram-se testes não paramétricos assumindo valor de $p<0,10$, como valor crítico de significância dos resultados. A escolha deve-se ao facto do número de enfermeiros com sintomatologia musculoesquelética ser reduzido.

\section{Resultados}

As características sociodemográficas e profissionais dos 260 participantes descrevem-se na Tabela 1. A maioria dos participantes é do género feminino, a exercer funções num horário maioritariamente rotativo. A idade dos participantes varia entre os 25 e 62 anos, sendo a idade média de 40,4 anos, com desvio padrão de 8,7. Relativamente ao tempo de profissão, 
o tempo mínimo é de 1 ano e o máximo de 43 anos, sendo o tempo médio de 16,6 anos, com um desvio padrão de 9 .

Relativamente à condição física, o índice de massa corporal (IMC) das enfermeiras varia entre os 17,6 e os 37,0. O maior número de enfermeiras encontra-se na classe de IMC saudável, sendo que o valor de IMC médio é 23,9. Os enfermeiros apresentam o IMC mínimo de 20,0 e existe um enfermeiro com IMC superior a 31,5, sendo que o IMC médio dos enfermeiros é de 25,8 (pré-obesidade).

Tabela 1

Caracterizaçâo sociodemográfica e profissional dos enfermeiros

\begin{tabular}{|c|c|c|c|}
\hline \multicolumn{2}{|c|}{ Caracterização da Amostra } & \multirow{2}{*}{$\begin{array}{c}n \\
50\end{array}$} & \multirow{2}{*}{$\frac{\%}{19,2}$} \\
\hline C'́nero & Masculino & & \\
\hline Genero & Feminino & 210 & 80,8 \\
\hline \multirow{4}{*}{ Idades } & {$[25-35[$} & 87 & $33,5 \%$ \\
\hline & {$[35-45[$} & 81 & $31,1 \%$ \\
\hline & {$[45-55[$} & 77 & $29,6 \%$ \\
\hline & {$[55-62]$} & 15 & $5,8 \%$ \\
\hline \multirow{5}{*}{ Habilitações } & Bacharelato & 2 & $0,8 \%$ \\
\hline & Licenciatura & 179 & $68,8 \%$ \\
\hline & Mestrado & 16 & $6,2 \%$ \\
\hline & Pós-Graduação & 17 & $6,5 \%$ \\
\hline & Especialidade & 46 & $17,7 \%$ \\
\hline \multirow{6}{*}{ Especialidade } & Médico - Cirúrgica & 28 & $30,9 \%$ \\
\hline & Saúde Comunitária & 5 & $10,9 \%$ \\
\hline & Reabilitação & 9 & $19,6 \%$ \\
\hline & Saúde Infantil e Pediátrica & 1 & $2,2 \%$ \\
\hline & Saúde Materna e Obstetrícia & 1 & $2,2 \%$ \\
\hline & Saúde Mental e Psiquiatria & 2 & $4,3 \%$ \\
\hline \multirow{2}{*}{ Horário } & Diurno & 48 & $18,5 \%$ \\
\hline & Turnos & 212 & $81,5 \%$ \\
\hline \multirow{2}{*}{$\begin{array}{l}\text { Horas } \\
\text { Semanais }\end{array}$} & $<40 \mathrm{H}$ & 118 & $45,5 \%$ \\
\hline & $\geq 40 \mathrm{H}$ & 142 & $54,7 \%$ \\
\hline \multicolumn{2}{|l|}{ Total } & 260 & 100,0 \\
\hline
\end{tabular}

Nota. $n=$ número da amostra; $\%=$ percentagem da amostra.

Para avaliar a sintomatologia manifestada pelos enfermeiros foi aplicado o QNM. O número de participantes neste estudo foi de 260 enfermeiros, sendo que 175 desses profissio- nais apresentaram sensação de dor nos últimos 12 meses em pelo menos um dos segmentos corporais (Tabela 2), sendo a prevalência de queixas de $65,1 \%$. 
Tabela 2

Caracterização da sensação de dor, nos diversos segmentos anatómicos nos últimos 12 meses

\begin{tabular}{|c|c|c|c|c|c|c|c|c|c|c|}
\hline \multirow[b]{3}{*}{ Segmento } & \multicolumn{4}{|c|}{ Dor } & \multicolumn{6}{|c|}{ Qual segmento } \\
\hline & \multicolumn{2}{|c|}{ Não } & \multicolumn{2}{|c|}{ Sim } & \multicolumn{2}{|c|}{ Esquerdo } & \multicolumn{2}{|c|}{ Direito } & \multicolumn{2}{|c|}{ Ambos } \\
\hline & $n$ & $\%$ & $n$ & $\%$ & $n$ & $\%$ & $n$ & $\%$ & $n$ & $\%$ \\
\hline Coluna cervical & 64 & 24,6 & 196 & 75,4 & --- & ---- & --- & ---- & -.- & --.-- \\
\hline Ombros & 108 & 41,5 & 152 & 58,5 & 27 & 17,8 & 49 & 32,2 & 76 & 50,0 \\
\hline Cotovelos & 222 & 85,4 & 38 & 14,6 & 8 & 21,1 & 15 & 39,5 & 15 & 39,5 \\
\hline Punho/Mãos & 168 & 64,6 & 92 & 35,4 & 11 & 12,0 & 40 & 43,5 & 41 & 44,6 \\
\hline Coluna dorsal & 106 & 40,8 & 154 & 59,2 & -.- & -.-- & $\ldots$ & -.- & $\ldots$ & -..- \\
\hline Coluna lombar & 60 & 23,1 & 200 & 76,9 & -.-- & -..-- & $\ldots$ & -.-- & $\ldots$ & -..- \\
\hline Ancas/Coxas & 184 & 70,8 & 76 & 29,2 & -.- & ---- & --- & -.-- & --- & -..- \\
\hline Pernas/Joelhos & 136 & 52,3 & 124 & 47,7 & --- & -.-- & -.- & --- & -.-- & -.-- \\
\hline Tornozelos/Pés & 205 & 78,8 & 55 & 21,2 & --- & -.--- & --.- & -.-- & --- & -.-- \\
\hline
\end{tabular}

Nota. $n=$ número da amostra; \% = percentagem da amostra.

Como se evidencia na Tabela 2, o segmento identificado com mais queixas é a coluna lombar $(76,9 \%)$, seguida da coluna cervical $(75,4 \%)$ e da coluna dorsal $(59,2 \%)$. Os segmentos anatómicos menos identificados com sensação de dor musculoesquelética são os cotovelos $(14,6 \%)$.

Em relação aos fatores de risco, apresentar-se-ão os aspetos de caráter individual e organizacional. Nas tabelas seguintes, observa-se a correlação encontrada entre os diferentes fatores de risco e a sintomatologia musculoesquelética.

Os fatores de risco individuais abordados são o género, a idade, o IMC e as habilitaçôes literárias, procurando conhecer de que forma estão relacionadas com o sensação de dor nos últimos 12 meses (Tabela 3; Tabela 4).

Relativamente ao género do profissional e à sensação de dor musculoesquelética nos últimos 12 meses, nos segmentos da coluna dorsal, ancas/coxas e pernas/joelhos, conclui-se que a proporção de enfermeiras que sentem dor nestes segmentos é superior à dos enfermeiros. Comparativamente, nos restantes segmentos corporais admite-se que as proporçôes de profissionais que sentem dor e que não sentem dor são iguais para os enfermeiros e para as enfermeiras, ou seja, não existe relação entre o género e o sensação de dor nos respetivos segmentos.

Quanto à idade e à sensação de dor nos últimos 12 meses observa-se que, no segmento da coluna dorsal, a idade média dos enfermeiros que sentiram dor é inferior à dos que não sentiram, ou seja, a sensação de dor na coluna dorsal diminui com a idade. Nos segmentos anatómicos cotovelos e tornozelos/pés, conclui-se que a idade média dos enfermeiros que sentiram dor é superior à dos que não sentiram, ou seja, a sensaçáo de dor nestes segmentos aumenta com a idade. Nos restantes segmentos anatómicos admite-se que a idade média dos enfermeiros que sentiram dor é igual à dos que não sentiram. Quanto ao IMC e à sensação de dor nos últimos 12 meses nos diversos segmentos corporais, é possível concluir que no segmento da coluna dorsal o IMC médio dos enfermeiros que sentiram dor é inferior ao dos que não sentiram. Nos restantes segmentos, admite-se que o IMC médio dos enfermeiros que sentiram dor é igual ao dos que não sentiram, ou seja, não existe relação entre o IMC e a sensação de dor.

Devido ao reduzido número de algumas habilitaçôes literárias por parte dos participantes, o Bacharelato e a Licenciatura foram agrupados numa só categoria designada por $1^{\circ}$ ciclo, ao mestrado e pós graduação foi atribuído o $2^{\circ}$ ciclo e, por último, o outro grupo é constituído pelos enfermeiros que apresentam a especialidade. Deste modo, no segmento da coluna dorsal, conclui-se que existem diferenças nas proporçóes de enfermeiros que sentem dor e que não sentem entre as diferentes habilitaçôes literárias. Após comparados os três níveis de habilitaçóes entre si, ou seja, $1^{\circ}$ ciclo e $2^{\circ}$ ciclo, admite-se que as proporções de enfermeiros que sentem e que não sentem dor são iguais 
para os dois ciclos. Relativamente ao $1^{\circ}$ ciclo e à especialidade, conclui-se que a proporção de enfermeiros que sentem dor na coluna dorsal é superior para os enfermeiros com o $1^{\circ}$ ciclo. Quando comparado o $2^{\circ}$ ciclo com a especialidade, a proporção de participantes que sentem dor na coluna dorsal é superior para os enfermeiros com o $2^{\circ}$ ciclo. Entre os três grupos de qualificaçôes académicas, verificou-se que os enfermeiros com a especialidade apresentam menos queixas no segmento da coluna dorsal. Nos restantes segmentos anatómicos, não existe diferenças entre os enfermeiros com o $1^{\circ}$ ciclo, o $2^{\circ}$ ciclo ou a especialidade.

Os fatores de risco organizacionais abordados são o tempo na profissão, os serviços onde desempenham funções, o tipo de horário e a carga horária semanal que os profissionais de enfermagem exercem (Tabela 3; Tabela 4).

Tabela 3

Correlação entre os fatores de risco e a sensação de dor nos últimos 12 meses utilizando o teste estatístico qui-quadrado

\begin{tabular}{|c|c|c|c|c|c|c|c|c|c|c|}
\hline \multirow{2}{*}{$\begin{array}{l}\text { Segmento } \\
\text { Anatómico }\end{array}$} & \multicolumn{2}{|c|}{ Género } & \multicolumn{2}{|c|}{$\begin{array}{c}\text { Habilitações } \\
\text { Literárias }\end{array}$} & \multicolumn{2}{|c|}{ Serviço } & \multicolumn{2}{|c|}{$\begin{array}{l}\text { Tipo de } \\
\text { horário }\end{array}$} & \multicolumn{2}{|c|}{$\begin{array}{c}\text { Carga Horária } \\
\text { Semanal }\end{array}$} \\
\hline & $X^{2}$ & $p$ & $X^{2}$ & $p$ & $X^{2}$ & $p$ & $X^{2}$ & $p$ & $X^{2}$ & $p$ \\
\hline Coluna Cervical & 1,4 & 0,244 & 4,7 & 0,653 & 4,7 & 0,096 & 0,391 & 0,532 & $<0,001$ & 0,999 \\
\hline Coluna Dorsal & 5,2 & 0,023 & 0,458 & 0,075 & 0,458 & 0,795 & 0,001 & 0,982 & 8,3 & 0,004 \\
\hline Coluna Lombar & $<0,001$ & 0,999 & 5,1 & 0,378 & 5,1 & 0,079 & 0,048 & 0,827 & 0,141 & 0,708 \\
\hline Ombros & 0,305 & 0,581 & 0,841 & 0,29 & 0,841 & 0,657 & 0,033 & 0,856 & 0,790 & 0,374 \\
\hline Cotovelos & 2 & 0,155 & $<0,001$ & 0,946 & $<0,001$ & 0,999 & 0,451 & 0,502 & 8,5 & 0,004 \\
\hline Punho/Mãos & 1,9 & 0,168 & 4,3 & 0,422 & 4,3 & 0,118 & 0,257 & 0,613 & 4,1 & 0,044 \\
\hline Ancas/Coxas & 6,1 & 0,014 & 0,464 & 0,239 & 0,464 & 0,793 & $<0,001$ & 0,999 & 0,679 & 0,41 \\
\hline Pernas/Joelhos & 6,9 & 0,009 & 3,0 & 0,448 & 3,0 & 0,227 & $<0,001$ & 0,999 & 0,646 & 0,422 \\
\hline Tornozelos/Pés & 0,64 & 0,424 & 1,5 & 0,343 & 1,5 & 0,222 & 0,843 & 0,359 & 1,2 & 0,281 \\
\hline
\end{tabular}

Nota. $p=$ nível de significância $(p<0,10) ; X^{2}=$ Estatística do Teste qui-quadrado.

Relativamente ao tempo na profissão e à sensação de dor, desconforto e fadiga musculoesquelética nos últimos 12 meses, foi possível observar que nos enfermeiros que apresentam dor nos segmentos anatómicos ombros, cotovelos, punho/mãos, ancas/coxas e tornozelos/pés, o tempo médio na profissão dos que sentiram dor é superior ao dos que não sentiram, ou seja, o sentimento de dor aumenta com o tempo de profissão. Contudo, no segmento da coluna dorsal, conclui-se que o tempo médio na profissão dos enfermeiros que sentiram dor é inferior ao dos que não sentiram, sendo que a sensação de dor diminui com o tempo de profissão. Nos restantes segmentos admite-se que não existe relação entre o tempo na profissão e a sensação de dor.

Procedeu-se também ao agrupamento por classes de serviço onde os enfermeiros exercem funçóes, nomeadamente, serviços da área cirúrgica, serviços da área médica e serviços de unidade, visto que o número de serviços encontrados na amostra é muito elevado. Em relação aos segmentos corporais, coluna cervical, coluna dorsal, coluna lombar, ombros, punho/mãos, ancas/coxas e pernas/joelhos, conclui-se que não existem diferenças nas proporçóes de enfermeiros que sentem dor e que não sentem entre os diferentes serviços. Quanto aos segmentos anatómicos cotovelos e tornozelos/pés não foi possível realizar o teste para os três serviços porque existem apenas dois e três enfermeiros dos serviços de unidade que sentiram dor. Deste modo, apenas se compararam os serviços da área cirúrgica e da área médica, admitindo-se que não existe relação entre o serviço onde os enfermeiros desempenham funções e a sensação de dor.

Quanto ao tipo de horário que os enfermeiros praticam, nomeadamente diurno ou o rotativo, 
admite-se que para todos os segmentos anatómicos as proporçôes de enfermeiros que sentem dor e que não sentem são iguais para os dois tipos de horário, ou seja, não existe relação entre o tipo de horário e a sensaçáo de dor. Relativamente à carga horária semanal que os enfermeiros praticam, foram definidas duas categorias, uma referente à carga semanal inferior a 40 horas, e outra, igual ou superior a 40 horas. No segmento anatómico da coluna dorsal, conclui-se que a proporção de enfermeiros que sentem dor é maior para os que têm uma carga horária de pelo menos 40 horas. Nos segmentos anatómicos cotovelos e punhos/ mãos conclui-se que a proporção de enfermeiros que sentem dor nos punhos/mãos é maior para os que têm uma carga horária inferior a 40 horas. Quanto aos restantes segmentos anatómicos, admite-se que as proporçôes de enfermeiros que sentem dor e que não sentem são iguais para ambas as cargas horárias.

\section{Tabela 4}

Correlação entre os fatores de risco e a sensação de dor nos últimos 12 meses utilizando teste estatístico Mann-Whitney

\begin{tabular}{lcccccc}
\hline & Tempo atual na profissão & \multicolumn{2}{c}{ Idade } & \multicolumn{2}{c}{ IMC } \\
\cline { 2 - 7 } & $U$ & $p$ & $U$ & $p$ & $U$ & $p$ \\
\hline Coluna Cervical & 6231 & 0,938 & 6228 & 0,934 & 6628 & 0,496 \\
\hline Coluna Dorsal & 9672,5 & 0,011 & 9909,5 & 0,003 & 9862,5 & 0,004 \\
\hline Coluna Lombar & 5959,5 & 0,938 & 6395 & 0,44 & 6121 & 0,814 \\
\hline Ombros & 7098,5 & 0,063 & 7478,5 & 0,222 & 7845,5 & 0,545 \\
\hline Cotovelos & 2981,5 & 0,004 & 2962 & 0,003 & 3917,5 & 0,484 \\
\hline Punho/Máos & 6417 & 0,024 & 6859,5 & 0,134 & 6834,5 & 0,124 \\
\hline Ancas/Coxas & 5906 & 0,049 & 6104,5 & 0,107 & 7226,5 & 0,671 \\
\hline Pernas/Joelhos & 7564,5 & 0,152 & 8121 & 0,608 & 8212,5 & 0,718 \\
\hline Tornozelos/Pés & 4665 & 0,049 & 4746,5 & 0,072 & 5426 & 0,67 \\
\hline
\end{tabular}

Nota. $p=$ nível de significância $(p<0,10) ; U=$ Teste Mann-Whitney

Para aferir se a utilização de equipamento de auxílio à prática de cuidados de enfermagem contribui para a diminuição do número de queixas musculoesqueléticas nos enfermeiros, foi analisada a distribuição da sensação de dor nos últimos 12 meses para os vários segmentos (Tabela 5). A utilização dos equipamentos no auxílio à transferência de doentes foi confirmada apenas por uma minoria dos participantes, 75 enfermeiros $(28,8 \%)$. No segmento corporal cotovelo conclui-se que a proporção de enfer- meiros que sentem dor é maior entre os que utilizam equipamento de auxílio à transferência de doentes do que entre os que náo utilizam. Contrariamente, nos restantes segmentos anatómicos pode admitir-se que as proporções de enfermeiros que sentem dor e que não sentem são iguais para os enfermeiros que utilizam e para os que não utilizam equipamento de auxílio à transferência de doentes, ou seja, não existe relação entre a utilização deste equipamento e a sensação de dor. 
Tabela 5

Correlação entre a utilização de equipamento de auxílio à prática de cuidados e a sensação de dor nos últimos 12 meses

\begin{tabular}{lcccccc}
\hline \multirow{2}{*}{ Segmento Anatómico } & \multicolumn{2}{c}{ Transferência de doentes } & $\begin{array}{c}\text { Atividades de higiene e } \\
\text { deambulação }\end{array}$ & $\begin{array}{c}\text { Auxílio à movimentação de } \\
\text { doentes na cama }\end{array}$ \\
\cline { 2 - 7 } & $X^{2}$ & $p$ & $X^{2}$ & $p$ & $X^{2}$ & $p$ \\
\hline Coluna Cervical & 0,09 & 0,76 & 0,241 & 0,623 & 0,005 & 0,941 \\
\hline Coluna Dorsal & 0,066 & 0,797 & 0,047 & 0,829 & 0,598 & 0,44 \\
\hline Coluna Lombar & 0,004 & 0,95 & 3,6 & 0,058 & 1,2 & 0,27 \\
\hline Ombros & 0,211 & 0,646 & 0,445 & 0,505 & 0,0005 & 0,983 \\
\hline Cotovelos & 6,4 & 0,01 & 4,4 & 0,035 & 0,069 & 0,793 \\
\hline Punho/Máos & 2,0 & 0,156 & 0,764 & 0,382 & $<0,001$ & $>0,999$ \\
\hline Ancas/Coxas & 0,03 & 0,862 & 0,736 & 0,391 & 0,332 & 0,564 \\
\hline Pernas/Joelhos & 0,225 & 0,635 & 2,1 & 0,143 & 0,476 & 0,490 \\
\hline Tornozelos/Pés & 0,3 & 0,584 & 3,2 & 0,076 & 0,604 & 0,437 \\
\hline
\end{tabular}

Nota. $p$ = nível de significância $(p<0,10) ; X^{2}=$ Teste qui-quadrado.

Quanto à utilização dos equipamentos no auxílio às atividades de higiene e de deambulação foi respondido afirmativamente por 94 enfermeiros $(36,2 \%)$. Nos segmentos anatómicos, coluna lombar, cotovelos e tornozelos/pés, conclui-se que a proporção de enfermeiros que sentem dor nestes segmentos é maior entre os que utilizam equipamento de auxílio às atividades de higiene e à deambulação do que entre os que não utilizam. Nos restantes segmentos corporais, admite-se que as proporçóes de enfermeiros que sentem dor e que não sentem são iguais para os enfermeiros que utilizam e para os que não utilizam os equipamentos.

Os enfermeiros que utilizam os equipamentos no auxílio à movimentação de doentes na cama correspondem a 54 enfermeiros (20,8\%). Nestes casos, em todos os segmentos anatómicos admite-se que as proporçôes de enfermeiros que sentem dor e que não sentem são iguais para os enfermeiros que utilizam e para os que não utilizam equipamento de auxílio à movimentação de doentes na cama.

\section{Discussáo}

Para além da determinação da prevalência da sintomatologia musculoesquelética dos enfermeiros no contexto hospitalar, este estudo procurou identificar os fatores de risco individuais e organizacionais, bem como determinar se os enfermeiros do $\mathrm{CH}$ em estudo utilizavam os dispositivos de auxílio durante a sua prática de cuidados. A amostra foi constituída pelos enfermeiros que exercem nos diversos serviços de internamento do Centro Hospitalar de Trás-os-Montes e Alto Douro (CHTMAD), com experiência profissional igual ou superior a 1 ano, sendo que $65,1 \%$ dos participantes apresentaram sensação de dor, desconforto e fadiga musculoesqueléticas nos últimos 12 meses. Pela análise dos resultados, podemos observar que o segmento anatómico da regiāo lombar $(76,9 \%)$ foi o que apresentou um maior número de queixas por parte dos enfermeiros, o que vai ao encontro de diversos estudos, nomeadamente, Cordeiro (2015), Torres et al. (2017) e Yan et al. (2017). Relativamente aos fatores de risco individuais e de carater organizacional, foi possível observar que houve relação entre alguns deles e a presença de dor nos últimos 12 meses. $\mathrm{O}$ género feminino apresenta mais queixas musculoesqueléticas ao nível dos segmentos da coluna dorsal, ancas/coxas e pernas/joelhos, tal como acontece no estudo de Lima et al. (2014), em que de facto, são as enfermeiras que mais queixas musculoesqueléticas apresentam $(47,4 \%)$ comparativamente com o género masculino $(18,6 \%)$. Pelo referido, depreende-se que o género feminino apresenta sensação de dor musculoesquelética superiores quando comparado com o género masculino. Já relativamente à idade, a dor musculoesquelética aumenta 
quanto maior for a idade, nos segmentos dos cotovelos e tornozelos/pés, contudo a dor na coluna dorsal diminui com a idade. Uma das explicaçóes para o mencionado pode ser o facto das enfermeiras que participaram no estudo serem maioritariamente jovens, possivelmente com filhos em idade pré-escolar, o que poderá potenciar as queixas nesse segmento corporal. Apesar do mencionado não ter sido estudado nesta investigação, constitui um aspeto a incluir noutras pesquisas. Importa referir que não se encontraram estudos que abordassem este dado. Relativamente às habilitaçóes literárias podemos observar que os enfermeiros com a especialidade apresentam menos dores na coluna dorsal que os enfermeiros licenciados, mestres ou com o bacharelato. Destes dados emerge a possibilidade de os conhecimentos apresentados pelos enfermeiros com especialidade culminarem na adoção de comportamentos preventivos, o que também constitui um aspeto pertinente a ser alvo de investigação futura. A maioria das enfermeiras apresentam um IMC considerado saudável, tal como acontece no estudo de Jerónimo (2013), e os enfermeiros apresentam maioritariamente pré-obesidade, o que se reflete no agravamento das queixas na coluna dorsal. Nos segmentos ombros, cotovelos, punhos/ mãos, ancas/coxas, pernas/ joelhos e tornozelos/ pés a dor aumenta com o tempo de profissão, contrariamente ao que acontece com a coluna dorsal. Este resultado está coerente com o mencionado anteriormente em relaçáo à idade das enfermeiras.

Podemos ainda constatar que a dor é maior para quem trabalha menos de 35 horas, nos segmentos anatómicos cotovelos e punhos/ mãos. Já ao nível da coluna dorsal pode observar-se que a dor é maior para quem trabalha pelo menos 40 horas.

Após a divisão dos serviços pelas diferentes áreas, contatou-se que não existe nenhuma relação entre os serviços onde os enfermeiros desempenham funçôes atualmente e a sensação de dor nos diversos segmentos corporais. Oliveira (2017), refere que a maior parte da população que abrange a regiáo de Trás-os-Montes e Alto Douro é maioritariamente envelhecida, com morbilidades e necessidades acrescidas, o que pressupóe que existem doentes com elevado nível de dependência, independentemente do serviço onde estes se encontram internados.
Para além do mencionado, constatou-se que a maior parte dos participantes apresenta comportamentos de risco durante o exercício profissional, mais concretamente o não uso dos equipamentos de auxílio à prática de cuidados. Apenas uma minoria dos enfermeiros é que utiliza os equipamentos de auxílio à prática de cuidados, nomeadamente, $28,8 \%$ dos profissionais que participaram no estudo utilizam os dispositivos de auxílio à transferência de doentes; $36,2 \%$ utilizam equipamentos de apoio durante a higiene e a deambulação e 20,8\% dos enfermeiros utilizam os equipamentos no auxílio à movimentação de doentes na cama. Torna-se, assim, importante relembrar os enfermeiros da existência destes equipamentos e da sua manipulação, caso contrário só apenas quando estes profissionais apresentarem dor ou patologia é que os vão utilizar. De facto, pelos resultados obtidos no nosso estudo depreendemos que os profissionais que sentiram dor procuraram utilizar alguns dos diversos equipamentos de auxílio à prestação de cuidados, em função desse mesmo desconforto. Martins (2008) verificou que 79,7\% e 78,6\% dos enfermeiros utilizam o elevador de transferência e o transfere. Pelo contrário, apenas $28,8 \%$ dos enfermeiros do CHTMAD os utilizam. No estudo de Torres et al. (2017), 88\% dos inquiridos referem a existência de meios de auxilio às atividades de transferência, mas que apenas $24 \%$ os utiliza em mais de $50 \%$ das situações, referindo um número reduzido de equipamentos nos serviços, a condição física do doente e o tempo excessivo de utilização e manuseamento difícil, como as principais razóes apontadas para a reduzida utilização dos equipamentos. Martins (2008) refere que os profissionais de enfermagem apresentam uma perceçáo do risco de desenvolvimento de sintomatologia musculoesquelética nas atividades de enfermagem e nas posturas que adotam durante a prestação de cuidados, no entanto, para diminuir o esforço físico e diminuir o risco em que a situação os coloca, utilizam frequentemente a colaboração do colega. Desta forma, apesar do enfermeiro apresentar competências para transferir corretamente um doente, o facto de estar constantemente a repetir esta tarefa durante o turno de trabalho e para com diferentes doentes, contribui para um risco agravado de lesão musculoesquelética. Face à problemática 
descrita ao longo deste artigo, Fernandes et al. (2018) e Serranheira, Cotrim, Rodrigues, Nunes e Sousa-Uva (2012), propóem a adoção de programas de intervençáo para a redução da sintomatologia musculoesquelética nos profissionais. Como exemplo, tem-se abordado a implementação de um programa multifatorial para a redução da sintomatologia musculoesquelética ligada ao trabalho, de acordo com a prevalência de lesóes, e de forma a colmatar uma mecânica corporal deficiente, bem como a falta de treino para técnicas de manuseamento de cargas (Fernandes et al., 2018). Para além disso, Torres et al. (2017) e Ribeiro (2015) identificam a importância da ginástica laboral como uma intervenção a ser executada para minorar o risco de lesóes musculoesqueléticas nos enfermeiros, uma vez que esta tem como objetivo a promoção da saúde do profissional, e relativamente à qual o EEER poderá ter um contributo fundamental.

Como limitações deste estudo, apontamos o facto de apenas ter sido realizado num $\mathrm{CH}$, bem como, a opção por uma técnica de amostragem não probabilística, o que poderá ter determinado o perfil dos participantes, nomeadamente, em relação à idade.

\section{Conclusão}

Os enfermeiros apresentam uma alta prevalência de desenvolvimento de sintomatologia musculoesquelética ligadas ao trabalho, sendo fundamental consciencializá-los para esta problemática. Pode concluir-se que a maioria dos enfermeiros manifesta sintomas ao nível do sistema musculoesquelético em pelo menos um segmento, sendo que as queixas mais frequentes se centram na coluna lombar, cervical e dorsal, o que corrobora os resultados de outros estudos já previamente realizados, quer no âmbito nacional ou internacional. Além disso, após analisados os fatores de risco que os enfermeiros apresentam, concluiu-se que é o fator tempo que mais condiciona o aparecimento destes sintomas. Quanto aos dispositivos de auxílio à prática de cuidados, observou-se que a maioria dos enfermeiros não os utiliza, ou quando recorre a estes é porque já apresenta sintomatologia associada. Para além disso, face aos resultados obtidos neste estudo, propomos o desenvolvimento de um programa que sensibilize os enfermeiros que desempenham funções nos serviços de internamento do hospital a prática de ginástica laboral de forma a minorar a sintomatologia musculoesquelética nesta classe profissional, e consequentemente reduzir as suas consequências. O EEER desempenhará aqui um papel de elevada importância, definindo e implementando o programa de forma a obter os objetivos propostos.

\section{Referências bibliográficas}

Agência Europeia para a Segurança e Saúde no Trabalho. (2019). Lesóes musculoesqueléticas. Recuperado de https://osha.europa.eu/pt/themes/musculoskeletal-disorders

American Nurses Association. (2011). 2011 ANA health \& safety survey. Recuperado de http://www.nursingworld.org/MainMenuCategories/WorkplaceSafety/ Healthy-Work-Environment/Work-Environment/ 2011-HealthSafetySurvey.html

Carpenter, H., \& Dawson, M. (2015). Keeping nurses healthy, safe, and well. American Nurse Today, 10(9), 6-8. Recuperado de https://www.americannursetoday.com/wp-content/uploads/2015/09/Special-Report-Workforce-Keeping.pdf

Cordeiro, A. R. (2015). Lesōes músculo-esqueléticas ligadas ao trabalho em enfermeiros: prevalência e fatores determinantes (Dissertação de mestrado). Instituto Politécnico de Viseu, Escola Superior de Saúde de Viseu, Portugal. Recuperado de http://repositorio. ipv.pt/handle/10400.19/3136

Direcção-Geral da Saúde. (2008). Lesões musculoesqueléticas relacionadas com o trabalho: Guia de orientação para prevenção. Lisboa, Portugal: Autor. Recuperado de https://www.dgs.pt/documentos-e-publicacoes/ lesoes-musculoesqueleticas-relacionadas-com-o-trabalho-pdf.aspx

Duarte, M. S., Gonçalves, N. R., Ferreira, G. N., \& Cunha, R. G. (2017). O impacto de um programa de ginástica laboral mensurado através do questionário nórdico de sintomas. Revista Cientifica de Saúde do Centro Universitário Belo-Horizonte, 10(1), 1-12. Recuperado de https://revistas.unibh.br/dcbas/article/ view/2007/pdf

Fernandes, C. S., Couto, G., Carvalho, R., Fernandes, D., \& Ferreira, P. (2018). Distúrbios osteomusculares relacionados ao trabalho autorreferidos por profissionais de saúde de um hospital em Portugal. Revista Brasileira de Medicina do Trabalho, 16(3), 353-359. 
doi: $10.5327 / Z 1679443520180230$

Jerónimo, J. M. (2013). Estudo da prevalência e factores de risco de lesöes musculoesqueléticas ligadas ao trabalho em enfermeiros (Dissertação de mestrado). Escola Superior de Enfermagem de Coimbra, Portugal.

Jerónimo, J., \& Cruz, A. (2014). Estudo da prevalência e factores de risco de lesóes musculoesqueléticas ligadas ao trabalho em enfermagem. Revista Investigação em Enfermagem, 9(9), 35-46. Recuperado de http:// www.eformasau.pt/files/Revistas/RIE9/RIE9_1.pd$\mathrm{f}$ \#page $=35$

Lima, A. C., Magnago, T. S., Prochnow, A., Ceron, M. D., Schardong, A. C., \& Scalcon, C. B. (2014). Fatores associados à dor musculoesquelética em trabalhadores de enfermagem hospitalar. Revista de Enfermagem UERJ, 22(4), 526-532. Recuperado de http://www. facenf.uerj.br/v22n4/v22n4a15.pdf

Martins, J. M. (2008). Percepçáo do risco de desenvolvimento de lesóes músculo-esqueléticas em actividade de enfermagem (Dissertação de mestrado). Universidade do Minho, Portugal. Recuperado de http://repositorium.sdum.uminho.pt/handle/1822/8169

Mesquita, C. C., Ribeiro, J. C. \& Moreira, P. (2010). Portuguese version of standardized Nordic musculoskeletal questionnaire: cross cultural and reliability. Journal of Public Health. doi:10.1007\%2 Fs10389-010-0331-0

Neves, M., \& Serranheira, F. (2014). A formação de profissionais de saúde para a prevençáo de lesóes musculoesqueléticas ligadas ao trabalho a nível da coluna lombar: Uma revisão sistemática. Revista Portuguesa de Saúde Pública, 32(1), 89-105. doi:10.1016/j. rpsp.2014.01.001

Oliveira, J. (2017). Relatório e contas 2017. Recuperado de http://chtmad.com/docs_internos/relatorio_contas_2017.pdf

Regulamento no 350/2015 de 22 de junho. Diário da República no 119/15 - II Série. Ordem dos Enfermeiros. Lisboa, Portugal.

Ribeiro, M. I. (2015). Avaliação das condiçóes de risco ergonómico dos trabalhadores no serviço de neurocirurgia (Dissertação de mestrado). Universidade do Porto, Instituto de Ciências Biomédicas Abel Salazar, Portugal. Recuperado de https://repositorio-aberto. up.pt/bitstream/10216/82510/2/113462.pdf

Santos, M., \& Almeida, A. (2012). Enfermagem na equipa de saúde ocupacional. Revista de Enfermagem Referência, 3(6), 147-155. doi:10.12707/RIII1195

Serranheira, F., Cotrim, T., Rodrigues, V., Nunes, C., \& Sousa-Uva, A. (2012). Lesões musculoesqueléticas ligadas ao trabalho em enfermeiros portugueses: «Ossos do ofício» ou doenças relacionadas com o trabalho? Revista Portuguesa Saúde Pública, 30(2),193-203. doi:10.1016/j.rpsp.2012.10.001

Torres, M., Carneiro, P., \& Arezes, P. (2017). LMERT em enfermeiros que prestam cuidados em contexto de internamento cirúrgico. International Journal on Working Conditions, 14, 33-49. Recuperado de http://ricot.com.pt/artigos/1/IJWC.14_Torres,Carneiro\&Arezes_p.33.49.pdf

Yan, P., Li, F., Zhang, L., Yang, Y., Huang, A., Wang, Y., \& Yao, H. (2017). Prevalence of work-related musculoskeletal disorders in the nurses working in Hospital of Xinjiang Uygur Autonomous region. Pain Research and Management, 2017(51), 1-7. doi: $10.1155 / 2017 / 5757108$ 
